\title{
Temporal-spatial Distribution Characteristics of Air Pollutants in Chengdu Economic Region, China
}

\author{
Hongjin Tong ${ }^{1}$, Sha Liu ${ }^{2}$, Ruixue Liao ${ }^{1}$, Xiaomei $\mathrm{Wei}^{2}$, Kangli Che ${ }^{2}$, Fenggang $\mathrm{Li}^{2}$, Wei Liu ${ }^{2}$ \\ ${ }^{1}$ Sichuan Academy of Environmental Science, Chengdu 610041, China \\ ${ }^{2}$ Chengdu University of Information Technology, Chengdu 610225, China
}

\begin{abstract}
The previous characteristics researches of air pollution were almost based on data from national environmental monitoring stations in 2015. The temporal variation curves of air pollutants and the ArcGIS grid interpolation method were used to analyze the spatial-temporal variation of air pollutants in five cities of Chengdu economic region. In 2015, the monthly change trends of $\mathrm{PM}_{2.5}, \mathrm{PM}_{10}, \mathrm{CO}, \mathrm{NO}_{2}$ and $\mathrm{NO}$ of air pollutants in Chengdu economic region were basically the same. The maximum monthly average concentration was in January or December, and the minimum was in May to September. The temporal variation of $\mathrm{SO}_{2}$ was characterized by little fluctuation of monthly concentration. The temporal variation characteristics of $\mathrm{O}_{3}$ were opposite to other pollutants. The spatial distribution of $\mathrm{PM}_{10}$ and $\mathrm{PM}_{2.5}$ was characterized by the largest concentration in Chengdu and the southwest of Meishan, in which they were mainly concentrated in the central area of Chengdu in winter. The average concentration of CO in Chengdu was the largest, followed by Deyang and Mianyang, and Meishan and Ziyang was the smallest. The concentrations of $\mathrm{NO}_{2}$ and $\mathrm{NO}$ in Chengdu were the largest, while those in Ziyang were the smallest. The spatial distribution characteristics of $\mathrm{O}_{3}$ were different from other pollutants. The areas with the largest concentration of $\mathrm{O}_{3}$ were Ziyang and a small part of west in Chengdu. The spatial distribution of $\mathrm{SO}_{2}$ was characterized by the largest concentration of $\mathrm{SO}_{2}$ in Ziyang, the lowest concentration in Mianyang and Deyang.
\end{abstract}

\section{Introduction}

With the rapid development of social economy, various kinds of harmful substances are continuously discharged into the air, which make the problem of air pollution more and more serious. Studies have shown that $\mathrm{PM}_{10}$ is one of the important factors leading to haze pollution ${ }^{[1,2]}$. In recent years, many studies have found that the increase of particulate matter can also lead to respiratory and cardiovascular system diseases and the increase of the mortality, which is a serious threat to health of the residents in the city, in addition it also has a great influence on atmospheric visibility.

Since the 1930s, air pollution events have been emerging in many developed countries abroad, where researchers began to study atmospheric pollution and have made great achievements in many countries. Winkler ${ }^{[3]}$ analyzed the change of the substance over time based on the monitoring data of atmospheric deposition rate, total precipitation rate and $210 \mathrm{pb}$ concentration in the air of southern Germany from 1972 to 1999 . Juliette ${ }^{[4]}$ investigated $\mathrm{PM}_{10}$ pollution events in a north sea trading port through relevant data provided by the meteorological station, and analyzed the spatial and temporal changes of concentrations of $\mathrm{SO}_{2}, \mathrm{PM}_{10}, \mathrm{O}_{3}$ and NO. LubosMaicek ${ }^{[5]}$ used spatial interpolation method of geographical information system (GIS) to analyze the spatial and temporal characteristics of environmental pollution in Prague. Bytnerowicz ${ }^{[6]}$ selected the most appropriate model to study the forests of the Dalbachus Mountains in Central Europe and analyzed the temporal and spatial distribution characteristics of ozone and air pollutants by comparing different spatial interpolation models (IDW, Kriging, Cokriging, Spline). In the French city of Mulhouse, Chantal ${ }^{[7]}$ used the geostatistical analysis method to generate the spatial distribution map of the concentration of $\mathrm{NO}_{2}$ in 2001 and analyzed its spatial distribution characteristics. Researchers ${ }^{[8]}$ applied air quality data and interpolation method of space and time at 23 stations around Paris daily NO concentration measurement, then the Paris region spatial and temporal variations of 19 stations NO observations were analyzed. $\mathrm{Li}^{[4]}$ analyzed the spatial and temporal distribution of air quality in Urumqi based on the concentration data of air pollutants in recent years. Considering the influence of meteorological conditions, regional total atmospheric control methods and terrain conditions on the total atmospheric control results, Guqing ${ }^{[9]}$ believed that the heating period was the optimal period for the total base control period, and also investigated the application of total atmospheric pollution control software. Researchers analyzed data from 31 main cities of China to assess the time-varying characteristics of air quality ${ }^{[10]}$. Using the indicator kriging method, people obtained the indicator 
function in the field of atmospheric environment research, and analyzed the spatial variation characteristics of $\mathrm{SO}_{2}$ in a city according to the indicator function, then estimated the spatial distribution of $\mathrm{SO}_{2}$, and finally obtained the relationship between the estimated error and the location of monitoring points ${ }^{[11]}$.

Chengdu economic region includes five cities which are Chengdu, Deyang, Mianyang, Meishan and Ziyang. Its special geographical environment, climatic and meteorological characteristics and urban planning requirements have put forward higher requirements for the atmospheric environmental quality of Chengdu economic zone. Therefore, this paper takes the monthly average concentration of atmospheric conventional pollutants in 2015 as the research object, and analyzes the spatial and temporal variation characteristics of pollutants in this region to further grasp the status of atmospheric environmental pollutants.

\section{Materials and methods}

Data of 2015 Sichuan state-controlled environmental air monitoring and the specific latitude and longitude of the national air quality monitoring points were collected. At present, many research methods are applied to analysis air pollution, such as linear correlation analysis, grey correlation analysis, single index method of environmental air quality, fuzzy mathematics method and Spearman rank correlation coefficient method in statistical analysis, in which the changes of atmospheric

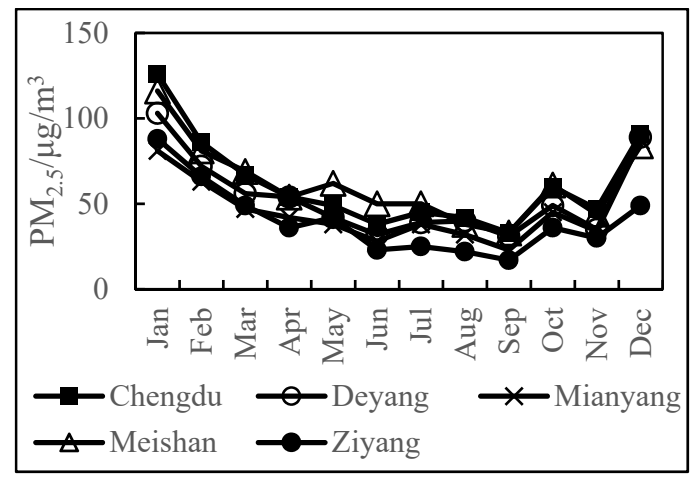

(a)

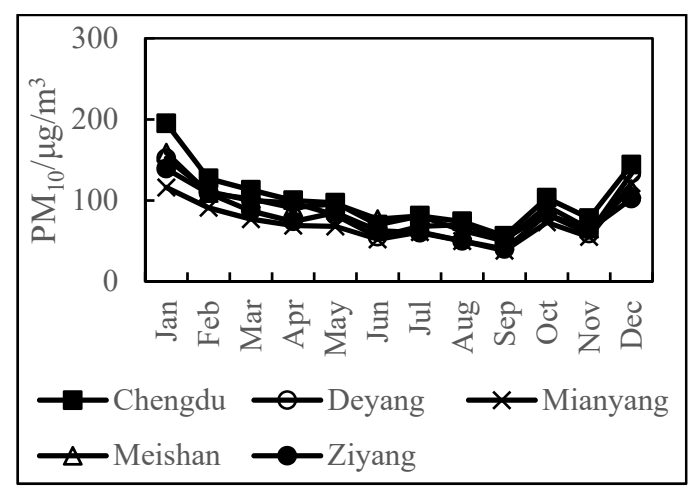

(b) environment are mainly analyzed by statistical methods $^{[12]}$

In this paper, the time distribution characteristics of air pollutants are analyzed by the time change curve of air pollutants, and the spatial changes of air pollutants in Chengdu economic zone are analyzed by ArcGIS grid interpolation method.

\section{Temporal and spatial variation of Chengdu economic region, China}

\subsection{Temporal variation of Chengdu economic region, China}

Figure 1 shows the changes of each pollutant monthly average concentration of Chengdu, Deyang, Mianyang, Meishan, and Ziyan in 2015. According to the monthly changes of air pollution characteristics, the concentration of $\mathrm{PM}_{2.5}, \mathrm{PM}_{\mathrm{we}}, \mathrm{CO}, \mathrm{NO}_{2}$ and $\mathrm{NO}$ in January and in December are largest, and the concentration is lower in June and November, and the lowest concentration occurs in June, September and November. The largest concentration of $\mathrm{O}_{3}$ was in May, and the highest concentration of Ziyang was in April, followed by July, and the lowest concentration was in January, November and December. The concentrations of $\mathrm{SO}_{2}$ in Chengdu, Deyang, Mianyang, Meishan change little. Only the change of $\mathrm{SO}_{2}$ in Ziyang is abnormal, the concentration of it in January, February and March is much larger than that in other months, while it starts to stabilize after May.

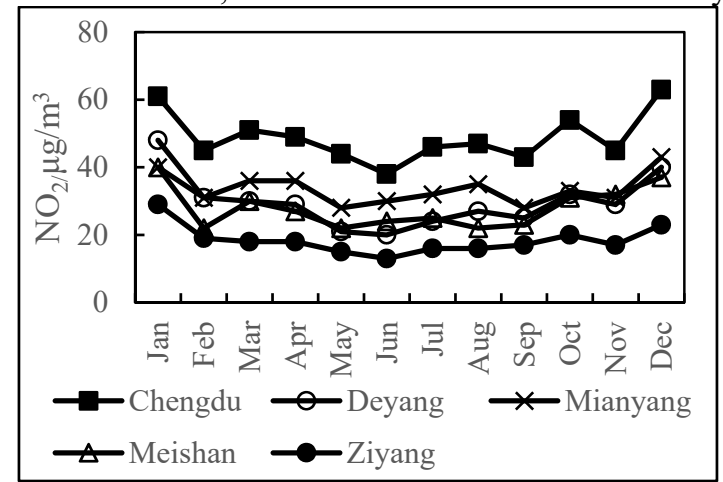

(d)

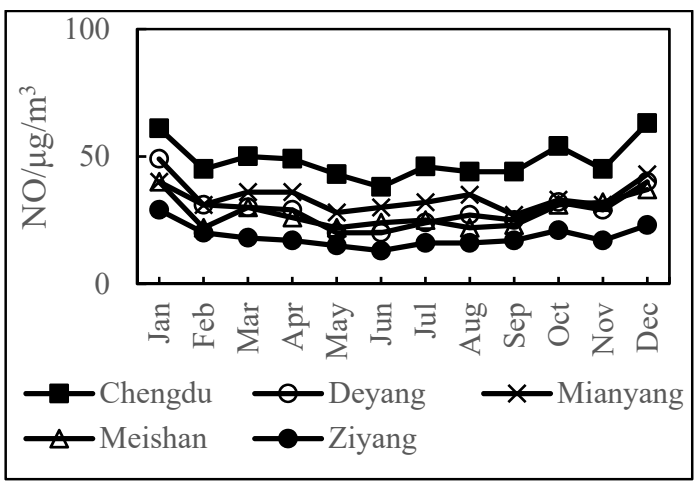

(e) 


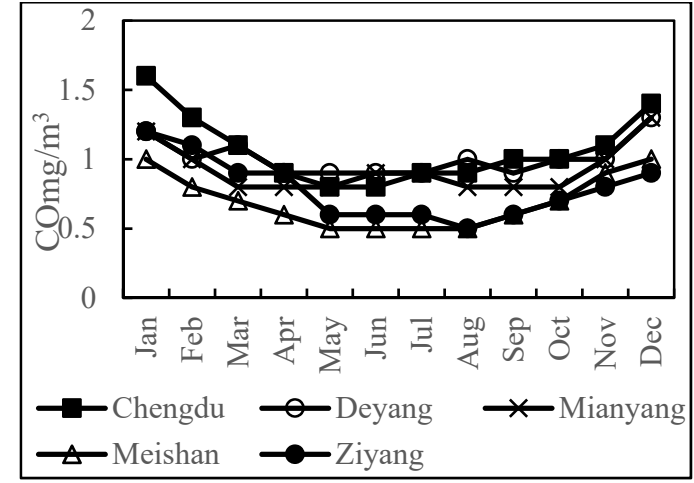

(c)

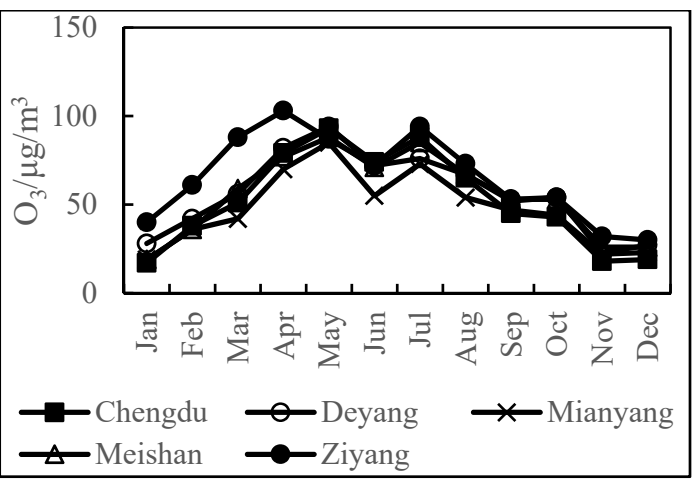

(f)

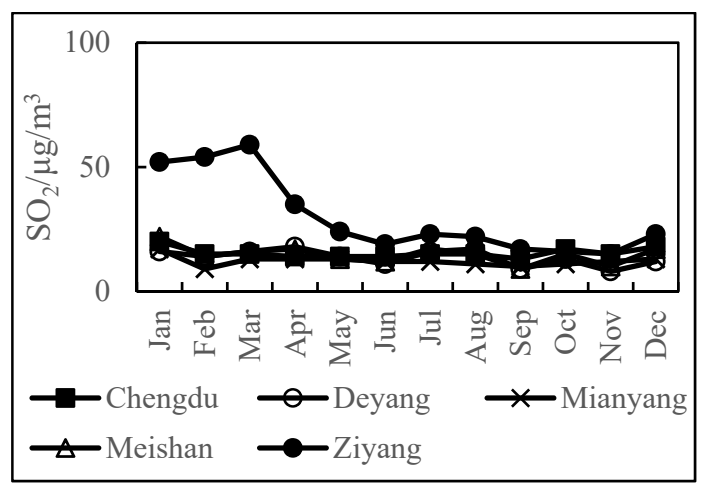

(g)

Fig. 1. Monthly variations of seven kinds of air pollutants in cities of Chengdu economic region from January to December in 2015 $\mathrm{PM} 2.5(\mathrm{a}) 、 \mathrm{PM} 10(\mathrm{~b}) 、 \mathrm{CO}(\mathrm{c}) 、 \mathrm{NO} 2(\mathrm{~d}) 、 \mathrm{NO}(\mathrm{e}) 、 \mathrm{O} 3(\mathrm{f}) 、 \mathrm{SO} 2(\mathrm{f})$

Statistical analysis of each pollutant monthly average concentration changes of Chengdu economic region was showed in figure 2 in 2015. The monthly concentration of pollutants changed significantly. The change trends of $\mathrm{PM}_{2.5}, \mathrm{SO}_{2}, \mathrm{NO}_{2}, \mathrm{NO}$ and $\mathrm{CO}$ were basically the same, which showed that the $\mathrm{PM}_{2.5}$ was larger from December to January and smaller from June to September, and the maximum value appeared in January. In general, the distributions of those are low in summer and high in winter. Due to Chengdu's special terrain, low wind speed and less rainfall, the pollutants are not easy to spread, so it is easy to cause particle pollution in winter, especially in December and January. The minimum of $\mathrm{PM}_{2.5}, \mathrm{SO}_{2}$ and $\mathrm{PM}_{10}$ appeared in September, the minimum of $\mathrm{NO}_{2}$ and NO appeared in June, and the minimum of CO appeared in May. Therefore, the air pollution in the Chengdu economic region was most serious during December and January, and light pollution from June to September. Due to the increase of light intensity, the photochemical reaction is enhanced, resulting in the highest concentration of $\mathrm{O}_{3}$ in May.

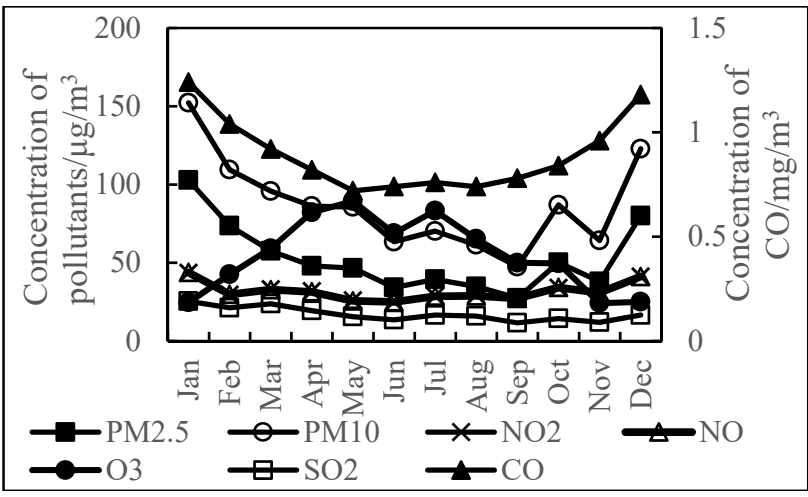

Fig. 2. Monthly distribution of PM2.5, PM10, CO, NO2, NO, $\mathrm{O} 3$ and $\mathrm{SO} 2$ concentrations in region economic of Chengdu in 2015

\subsection{Spatial variation of Chengdu economic region, China}

Figure 3 showed the spatial distribution characteristics of the annual average concentration of $\mathrm{PM}_{2.5}, \mathrm{PM}_{10}, \mathrm{CO}$, $\mathrm{NO}_{2}, \mathrm{NO}, \mathrm{O}_{3}$ and $\mathrm{SO}_{2}$ in Chengdu economic region in 2015. The largest annual average concentration $\mathrm{PM}_{2.5}$ in Chengdu economic region in 2015 was Chengdu and most areas of Meishan in the southwest, followed by Deyang. As the distance increases, the concentration of $\mathrm{PM}_{2.5}$ decreases slowly. The lowest annual concentration of $\mathrm{PM}_{2.5}$ is Ziyang. The highest annual average concentration 
of $\mathrm{PM}_{10}$ is in the central region of Chengdu, and then it gradually decreases to the surrounding area, and the lowest is in Mianyang, which means that Chengdu is the main contaminant of $\mathrm{PM}_{10}$. The largest concentration of $\mathrm{CO}$ is Chengdu, and the second is Deyang, and the lowest is the southern part of the Ziyang and the south of Meishan. The maximum annual concentration of $\mathrm{NO}_{2}$ and NO appeared in Chengdu, and the lowest appeared in the

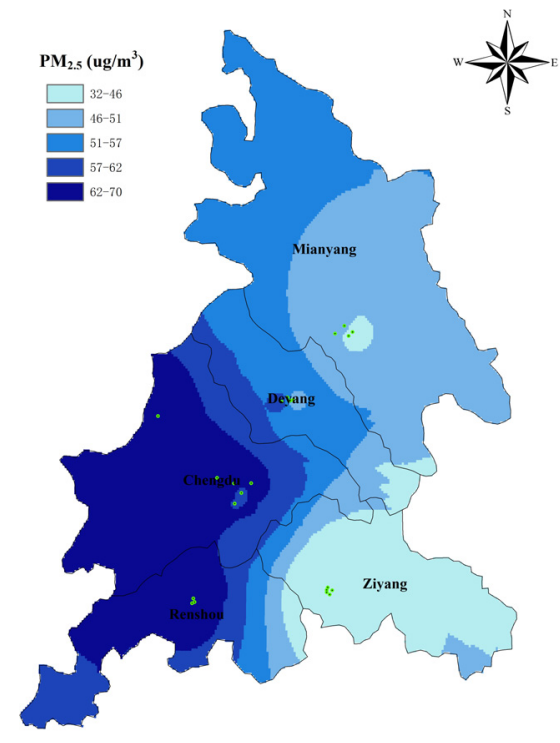

(a)

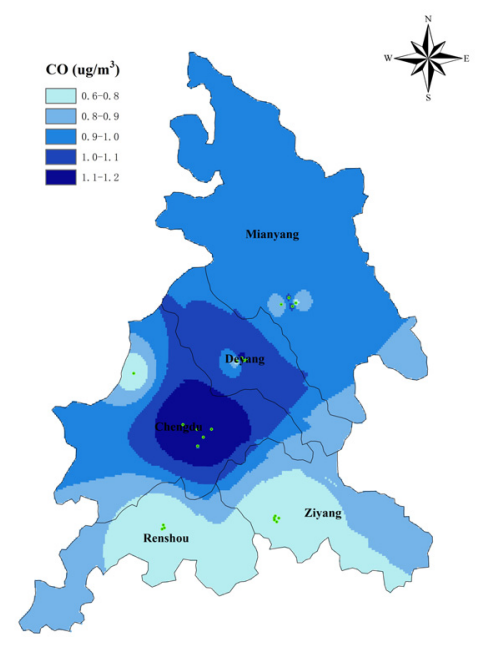

(c) southeast of Ziyang and a small area in the east of Meishan. The highest annual concentration of $\mathrm{O}_{3}$ is in Ziyang, and the lowest is in Mianyang and Chengdu. In 2015 , the largest annual average concentration of $\mathrm{SO}_{2}$ in Chengdu economic region was in Ziyang, and it tended to spread to the surrounding areas; the lowest concentrations were in Mianyang and Deyang.

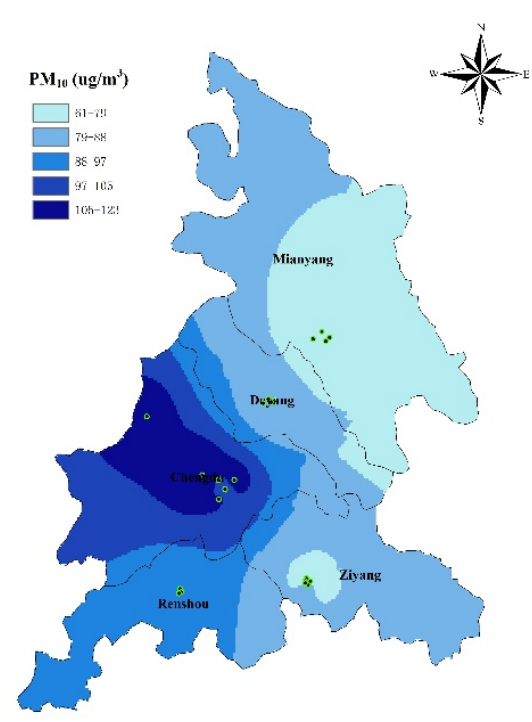

(b)

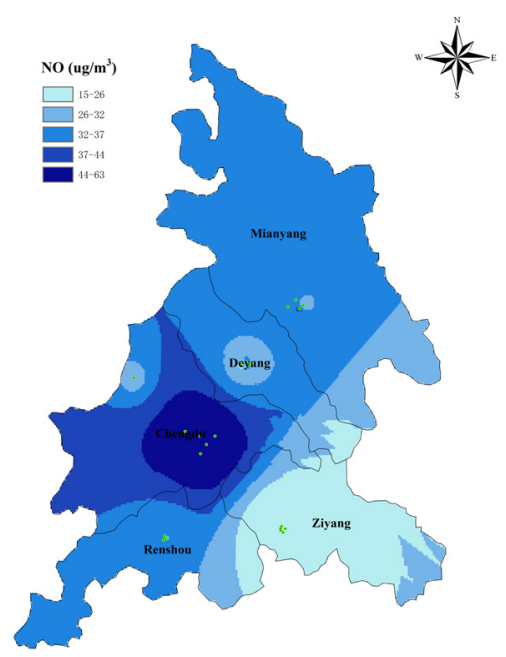

(e) 


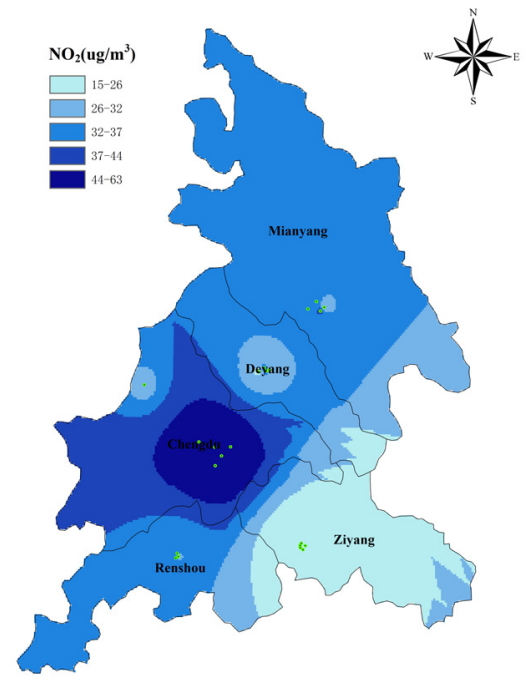

(d)

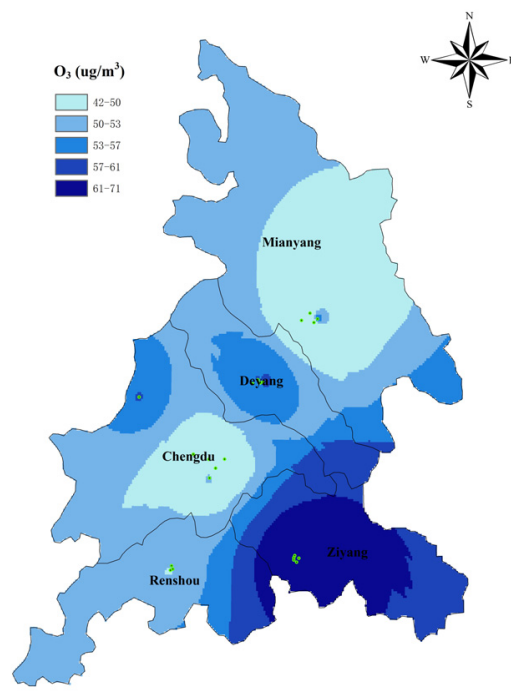

(f)

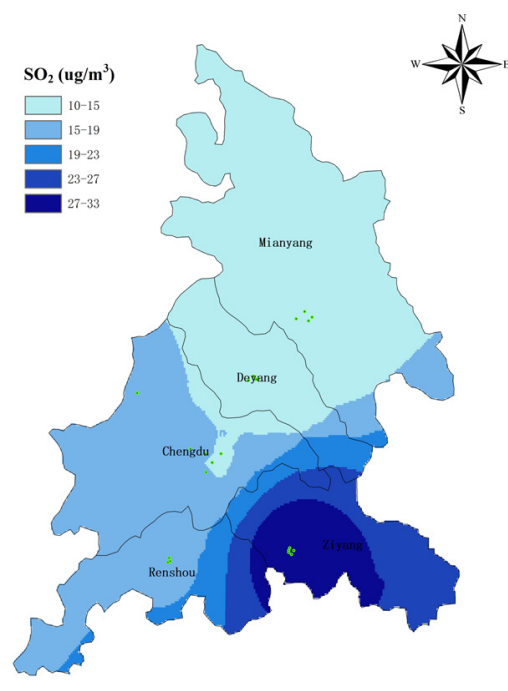

(g)

Fig. 3. Spatial distribution of annual average concentrations of seven air pollutants in Chengdu economic region in 2015 PM2.5(a)、 $\mathrm{PM} 10(\mathrm{~b}) 、 \mathrm{CO}(\mathrm{c}) 、 \mathrm{NO} 2(\mathrm{~d}) 、 \mathrm{NO}(\mathrm{e}) 、 \mathrm{O} 3(\mathrm{f}) 、 \mathrm{SO} 2(\mathrm{f})$

\section{Results and discussion}

(1) In the year of 2015, the changing trends of monthly average concentration of $\mathrm{PM}_{2.5}, \mathrm{PM}_{10}, \mathrm{CO}, \mathrm{NO}_{2}$ and $\mathrm{NO}$ in Chengdu Economic Zone were almost the same. The highest monthly concentration occurred in January or December, and the lowest appeared in May to September. The monthly variation characteristics of $\mathrm{O}_{3}$ concentration were opposite to other pollutants. The highest monthly concentration of $\mathrm{O}_{3}$ occurred in May in the district of Chengdu, Deyang, Mianyang, Meishan, while the highest monthly average concentration of $\mathrm{O}_{3}$ in ziyang occurred in April, and that in January. November and December were the lowest in all regions. As for $\mathrm{SO}_{2}$, the monthly average concentration of $\mathrm{SO}_{2}$ in Chengdu, Deyang, Mianyang and Meishan changed little, while the monthly average concentration of it in Ziyang is larger than that of the other four cities.

(2) From the spatial distribution characteristics of $\mathrm{PM}_{10}$ and $\mathrm{PM}_{2.5}$, the concentrations of them are the largest in Chengdu and the southwest region of Meishan, and the two pollutants in winter mainly occur in the central area of Chengdu. The lowest concentration of $\mathrm{PM}_{10}$ and $\mathrm{PM}_{2.5}$ occur in Mianyang. The spatial distribution of $\mathrm{CO}$ is the largest in Chengdu, followed by Deyang and Mianyang, while the concentration of $\mathrm{CO}$ in Meishan and Ziyang is the smallest. The spatial distribution characteristics of $\mathrm{NO}_{2}$ are the same as those of $\mathrm{NO}$, with the largest concentration in Chengdu and the smallest in Ziyang. The spatial distribution characteristic of $\mathrm{O}_{3}$ is different from other pollutants. The areas with the highest concentration of $\mathrm{O}_{3}$ are Ziyang and a small part of western Chengdu. The spatial distribution characteristics of $\mathrm{SO}_{2}$ indicate that 
the largest concentration of $\mathrm{SO}_{2}$ occurs in Ziyang, and the concentration in Mianyang and Deyang is the lowest.

\section{Reference}

1. P. Praphatsorn, C. Somporn, Identification of potential sources of PM10 pollution from biomass burning in northern Thailand using statistical analysis of trajectories. Atmos. Pollut. Res. 9, 1038-1051 (2018)

2. L. Xiaohong, J. Keshen, Analyzing effect of urbanization on haze pollution based on static and dynamic spatial panel model. Transactions of the Chinese Society of Agricultural Engineering 33, 218-225 (2017)

3. R.Winkler, G. Rosner, Seasonal and long-term variation of $210 \mathrm{~Pb}$ concentration in air, atmospheric deposition rate and total deposition velocity in south Germany. Sci. Total Environ. 263, 57-68 (2000)

4. L. Mo, Study on spatial and temporal distribution of air pollution in urumqi. Drought environment monitoring 23, 223-226 (2009). (in chinese)

5. L. Matějíček, P. Engst, Z. Jaňour, A GIS-based approach to spatio-temporal analysis of environmental pollution in urban areas: A case study of Prague's environment extended by LIDAR data. Ecol. Modell. 199, 261-277 (2006)

6. A. Bytnerowicz, B. Godzik, W. Fraczek,
Distribution of ozone and other air pollutants in forests of the Carpathian Mountains in central Europe. Environ. Pollut. 1, 3-25 (2002)

7. C. De Fouquet, D. Gallois, G. Perron, Geostatistical characterization of the nitrogen dioxide concentration in an urban area-Part I: Spatial variability and cartography of the annual concentration. Atmos. Environ.41,6701-6714 (2007)

8. R. Romanowicz, P. Young, P. Brown, P. Diggle, A recursive estimation approach to the spatiotemporal analysis and modelling of air quality data. Environ. Modell. and Soft. 21, 759-769 (2006)

9. G. Qing, Baseline and methods for China's regional total atmospheric control. China Environ. Sci. 25-28 (2000). (in chinese)

10. Z. Zixiang, G. Xiumei, W. Huaqing, Y. Jie, Evaluating air quality in China based on daily data: Application of integer data envelopment analysis. $J$. Clean. Prod. 198, 304-311 (2018)

11. M. jian, M. xiaoming, Kriging space analysis and its application in urban air pollution. Mathematical practice and cognition 32, 309-312 (2002). (in chinese)

12. Y. Jing, S. Kaihui, H. Jian, Z. Peidong, W. Jinhu, Temporal and spacial dynamics of bioenergy-related $\mathrm{CO}_{2}$ emissions and underlying forces analysis in China. Renew. Sust. Energ. 70 1323-1330 (2017) 